\title{
Snowmelt Infiltration into Alpine Soils Visualized by Dye Tracer Technique
}

\author{
Manfred Stähli,* \\ Daniel Bayard, $\dagger$ \\ Hannes Wydler, $\ddagger$ and \\ Hannes Flühler $\ddagger$ \\ *Swiss Federal Research Institute WSL, \\ Water, Soils and Rock Movements, \\ Zürcherstrasse 111, \\ CH-8903 Birmensdorf, Switzerland. \\ manfred.staehli@wsl.ch \\ $\dagger$ EPF Lausanne, Geolep, ENAC, \\ CH-1015 Lausanne, Switzerland. \\ d.bayard@pmodwrc.ch \\ $\$$ Institute of Terrestrial Ecology, \\ ETH Zürich, Grabenstrasse 3, CH-8952 \\ Schlieren, Switzerland. \\ fluehler@ito.umnw.ethz.ch \\ wydler@ito.umnw.ethz.ch
}

\begin{abstract}
Snowmelt infiltration into alpine soils can be severely reduced and even impeded by soil frost. In order to learn more about the true nature of infiltration pathways into alpine soils, dye tracer experiments were set up at 2 locations in southern Switzerland: at Hannigalp $(2100 \mathrm{~m})$ and at Gd St Bernard. Over the course of two winters (2000-2001 and 20012002) we excavated vertical soil profiles during snowmelt to examine the distribution of a dye tracer (Brilliant Blue FCF) that had been applied on the surface of a $7-\mathrm{m}^{2}$ plot at the beginning of the winter. Soil conditions varied between the winters, with the soils remaining unfrozen during the first and a significant frozen layer forming during the second. With this method the dominant infiltration processes at these 2 sites were identified. During the first winter the water infiltration at Hannigalp showed a pronounced preferential behavior, whereas at Gd St Bernard we found a more homogeneous front-like infiltration. During the second winter the impeding impact of the frozen soil was clearly seen at the Hannigalp site-however, only in the first stage of the snowmelt. More decisive for the formation of lateral surface runoff was the buildup of an ice layer on the soil surface due to melting and refreezing. Cold-chamber experiments, in which intact soil columns were irrigated with a dye tracer and a fluorescent tracer solution, confirmed our in situ observations with regard to heterogeneity and soil frost effect on the infiltration pattern. Our study showed that both tracers can be applied to frozen soil in the laboratory, whereas at the remote alpine locations only the dye tracer method was applicable.
\end{abstract}

\section{Introduction}

In alpine regions, a large portion of the annual water input to the terrestrial system occurs during spring snowmelt. As a benefit, the groundwater bodies get recharged, but extensive snowmelt in combination with rain may increase the risk of flooding or debris flows (Singh et al., 1997). Since soil frost alters the water flow paths at the surface by reducing infiltration capacity and enhancing surface runoff (Miller, 1980), the combination of snowmelt and frozen soil surfaces is of concern. The interactions between the seasonal snowpack development, the formation of soil frost, and the water fluxes during the late-winter melt season are very complex, in part due to the enormous variation in microclimate and soil conditions encountered in alpine areas. Very few field studies have been reported on the water transport in alpine soils in contrast to arable land and forests in the lowlands. Hence, there is little knowledge of the pattern of water flow paths from the melting snow cover into the frozen or unfrozen soil. In this paper, we present a method that provides both descriptive and quantitative information on the water flow paths from a melting snow cover into (frozen and unfrozen) alpine soils. The method is based on quasiconservative dye and fluorescent tracers applied to the soil surface at the beginning of the winter and detected in the soil at several stages of the snowmelt.

Flury et al. (1994), Forrer et al. (2000), Kulli et al. (2003), and others demonstrated the potential of dye tracers to visualize water flow in different types of (nonfrozen) agricultural soils. The method allows conclusions to be drawn about dominant flow processes and changes in water flow behavior due to human impacts (e.g., soil compaction). For soils with a homogeneous background color, the intensity of the dye tracers makes it possible to quantify the water infiltration (Forrer et al., 2000 ); in soils with a heterogeneous color, the water flow paths can be determined only qualitatively (i.e., stained or nonstained areas). Fluorescent tracers provide a more sophisticated method for quanti- fying soil water infiltration. Aeby et al. (2001) developed a method by which tracer concentration maps can be derived from the reflection image of fluorescent tracers recorded by a cooled charge coupled device $(\mathrm{CCD})$ camera.

Stadler et al. (2000) showed that both the dye and the fluorescent tracer method can also be used in frozen soils. They quantified infiltration rates into frozen soil columns with different water and ice contents in a cold-chamber experiment. However, an in situ dye tracer experiment with frozen soil conditions has not yet been attempted.

The objectives of this study were twofold:

1. To investigate whether the application of dye and fluorescent tracers is an appropriate methodology for studying water flow paths in alpine soils under (harsh) winter conditions.

2. To investigate the effects of frozen and unfrozen alpine soils on the water infiltration from melting snow.

Tracers were applied to soils at 2 very different locations in the southern Swiss Alps. In a cold-chamber experiment, they were also applied to soil columns collected from one of the 2 field sites. In the first part of the paper, we explain in detail the different steps of the experimental procedure, especially the image analysis to extract the infiltration flow paths. In the second part, we discuss the different flow patterns observed in the frozen and unfrozen soils.

\section{Materials and Methods}

\section{FIELD EXPERIMENTS}

\section{Site Description}

The field experiments were carried out at 2 alpine sites in southern Switzerland: Hannigalp (Grächen; $2100 \mathrm{~m}$ a.s.l.) and Gd St Bernard (2450 $\mathrm{m}$ a.s.1.). The site at Hannigalp (Fig. 1) is located in a moderately $(23 \%)$ sloping terrain facing northwest. Sparse Ericacea vegetation 


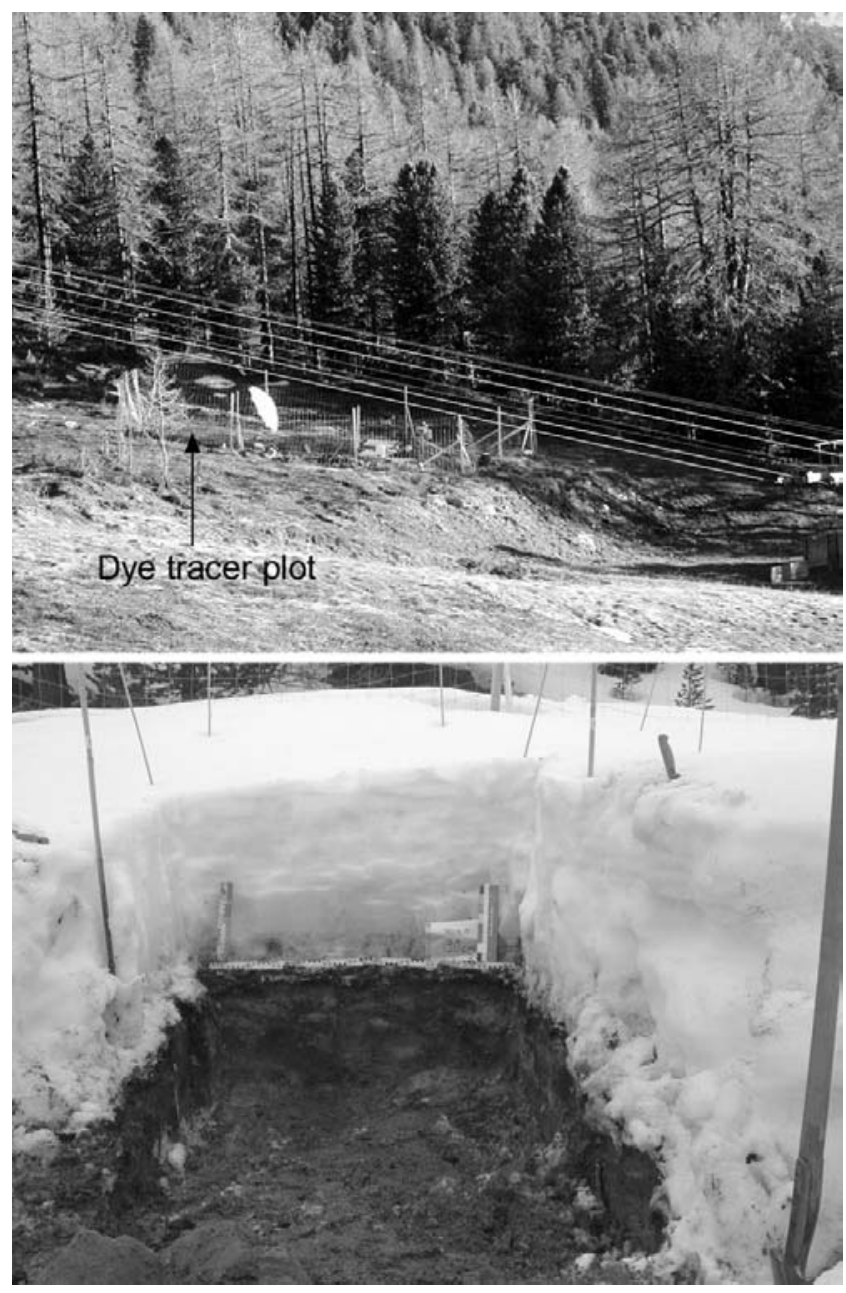

FIGURE 1. Top: View of the experimental site at Hannigalp (Grächen, $2100 \mathrm{~m}$ a.s.l.) shortly after the end of the snowmelt. Bottom: Example of an excavated profile on 30 April 2001 from which the flow pattern of the stained meltwater was analyzed.

covers the soil, which is a 60-to-80-cm-deep sandy ferric podzole above the bedrock. The soil profile is characterized by a heterogeneous pattern of reddish-brown color blending with pale-white leached horizons. The organic top layer is very shallow (about $1-2 \mathrm{~cm}$ ) and highly water repellent, which has been demonstrated with in situ drop infiltration tests (Bisdom et al., 1993). The physical properties of the soil, as determined in the laboratory, are summarized in Table 1 . The climate at Hannigalp is dry (mean annual precipitation $600 \mathrm{~mm}$ ) due to its protected location. The mean air temperature is $2^{\circ} \mathrm{C}$, and the normal winter season lasts from early November to the beginning of May.

At Gd St Bernard the experiment was set up on a rather steep (65\%) grassland slope with a southern exposure (Fig. 2). The soil is a 40-to-60-cm-deep ranker with a high content of flat slate stones. The soil matrix is dominated by silt and sand and contains 5 to $10 \%$ organic matter (Table 1). The meteorological conditions at Gd St Bernard are harsh, with a high annual precipitation $(2100 \mathrm{~mm})$ and frequently strong winds. The mean air temperature is $-1^{\circ} \mathrm{C}$, and the winter season may start in October and end in June.

\section{Fieldwork}

The in situ tracer experiments were carried out over 2 winters: at both sites in 2000-2001 and at Hannigalp only in 2001-2002. In autumn 2000 we selected suitable plots, which have a length of approximately $5 \mathrm{~m}$ and a width of $1-1.5 \mathrm{~m}$. The surface was photographed
TABLE 1

Physical properties of the soils at Hannigalp and Gd St Bernard

\begin{tabular}{|c|c|c|c|c|c|c|}
\hline $\begin{array}{c}\text { Soil } \\
\text { horizon } \\
(\mathrm{cm})\end{array}$ & $\begin{array}{c}\text { Sand } \\
\text { content } \\
(\%) \\
\end{array}$ & $\begin{array}{c}\text { Loam } \\
\text { content } \\
(\%)\end{array}$ & $\begin{array}{c}\text { Clay } \\
\text { content } \\
(\%)\end{array}$ & $\begin{array}{l}\text { Porosity } \\
\left(\mathrm{m}^{3} \mathrm{~m}^{-3}\right)\end{array}$ & $\begin{array}{c}\text { Bulk } \\
\text { density } \\
\left(\mathrm{g} \mathrm{cm}^{-3}\right)\end{array}$ & $\begin{array}{c}\text { Saturated } \\
\text { conductivity } \\
\left(10^{-5} \mathrm{~m} \mathrm{~s}^{-1}\right)\end{array}$ \\
\hline \multicolumn{7}{|c|}{ Hannigalp } \\
\hline $5-15$ & 63.20 & 30.40 & 6.50 & 0.551 & 1.09 & \\
\hline $15-25$ & 60.55 & 33.65 & 5.85 & 0.541 & 1.12 & \\
\hline $25-35$ & 57.90 & 36.90 & 5.20 & 0.508 & 1.12 & 3 \\
\hline \multicolumn{7}{|c|}{ Gd St Bernard } \\
\hline $0-7$ & 53.50 & 38.10 & 8.40 & 0.73 & 0.64 & \\
\hline $7-15$ & 48.80 & 40.85 & 10.35 & 0.59 & 0.90 & 5 \\
\hline $15-25$ & 44.10 & 43.60 & 12.30 & 0.57 & 0.90 & 5 \\
\hline
\end{tabular}

from above in order to map the heterogeneous distribution of the surface vegetation.

At the beginning of each winter a dye tracer was applied to the selected plots. We used the food dye Brilliant Blue FCF, which has been used in numerous soil physical field studies before (e.g., Flury et al., 1994; Forrer et al., 2000). Brilliant Blue FDF is nontoxic, easily visible in normal field soils, and, depending on the $\mathrm{pH}$, either neutral or anionic with a rather high mobility. Flury and Flühler (1995) demonstrated that in a loamy sand this tracer was only slightly retarded (relative retardation 1.2) compared to a conservative tracer (Iodit).

Two different procedures were attempted to evenly distribute the tracer as close as possible to the soil surface of the plots. Prior to the first winter the tracer was applied (as a powder) mixed into $5-10 \mathrm{~cm}$ of snow. For the second winter we applied the tracer (as a powder) directly on the bare soil surface and covered the plot with a plastic sheet to protect the tracer from rain and wind. Once a shallow snow cover had formed, we removed the plastic sheet and covered the tracer with a snow layer of about $10-15 \mathrm{~cm}$.

In late winter, we returned to the sites and excavated vertical profiles at the tracer plots. These were carried out at different stages of the snowmelt, starting at the onset and ending shortly after the complete melt of the snow. To minimize the influence of one excavation on the infiltration in the remaining, undisturbed portion of the plot, the profiles were dug out successively starting from the most downhill point of each plot. For each date, we excavated 2 to 4 profiles in total. The distance between successive profiles varied between 20 and $50 \mathrm{~cm}$. Each profile was then photographed using a digital camera (Nikon Coolpix 990) at a pixel resolution of less than $1.5 \mathrm{~mm}$. To compensate for differences in profile illumination due to different weather conditions during excavation, we shaded the profile with a parasol. After each excavation we refilled soil and snow to minimize disturbances within the remaining portion of the plot.

\section{COLD-CHAMBER EXPERIMENT}

Complementary to the field experiment, we also conducted tracer studies on soil samples in a cold chamber. For this purpose, 4 intact soil samples were collected $20 \mathrm{~m}$ south of the in situ tracer plots at Hannigalp, using steel cylinders with a diameter of $25 \mathrm{~cm}$ and a length of $60 \mathrm{~cm}$. The soil columns were brought to the laboratory, where a number of measurement probes (Time Domain Reflectometry, Thermistors, and Tensiometers) were inserted horizontally at 4 different depths to monitor the water and heat balance inside the samples (Fig. 3). At the base of each column, a suction plate was mounted to allow water to drain at nonsaturated conditions. The columns were then placed in a box filled with cork crumbs, which act as insulation and allow only vertical heat exchange at the soil surface, 

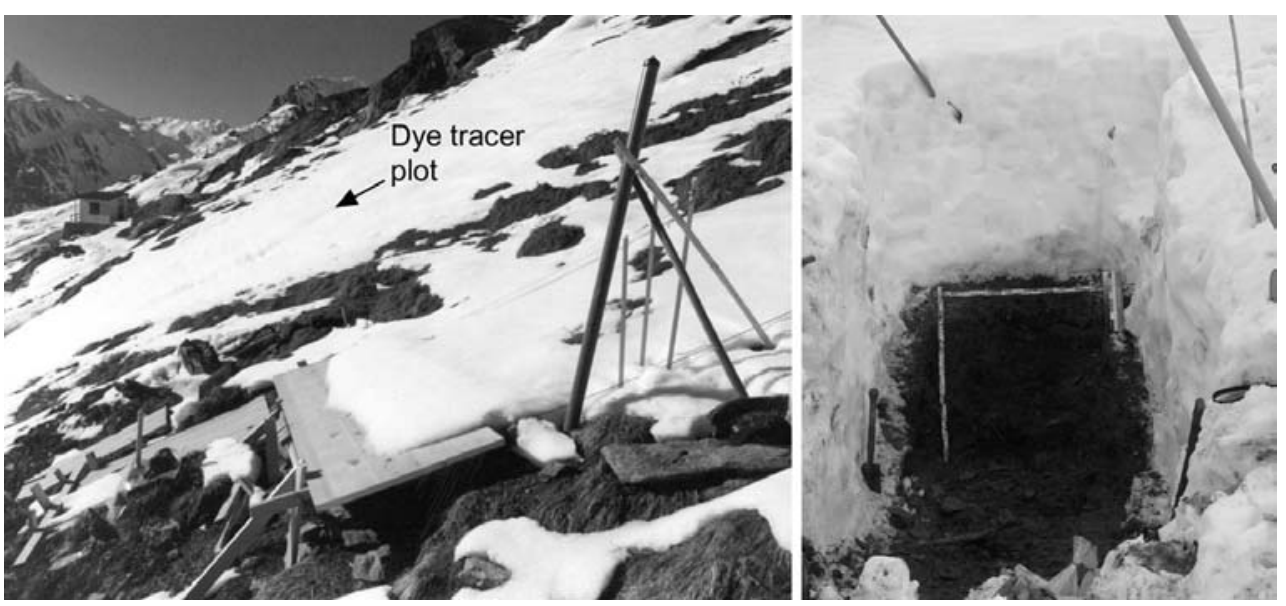

FIGURE 2. Left: View of the experimental site at Gd St Bernard, (2450 $m$ a.s.l.) at the beginning of the winter. Runoff measurement installations in the front. Right: Example of an excavated profile on 14 May 2001 from which the flow pattern of the stained meltwater was analyzed. resulting in natural downward freezing. Two of the columns were subjected to freezing (to a depth of about $20-30 \mathrm{~cm}$ ), whereas the other 2 samples remained unfrozen. A rotating sprinkling device located above the columns irrigated the columns for $6 \mathrm{hr}$ at a rate of 5 to $7 \mathrm{~mm}$ $\mathrm{hr}^{-1}$. The applied solution contained $2 \mathrm{~g} \mathrm{~L}^{-1}$ Brilliant Blue FCF as well as $2 \mathrm{~g} \mathrm{~L}^{-1}$ Brilliant Sulvaflavine, a fluorescent tracer (Aeby et al., 2001). During the irrigation, the chamber temperature was $2^{\circ} \mathrm{C}$.

Immediately following irrigation, the columns were entirely refrozen (to $-8^{\circ} \mathrm{C}$ ) to preserve the water distribution inside the column. A few days later, the frozen samples were sectioned using a circular saw: first, the columns were horizontally sectioned at a depth of $30 \mathrm{~cm}$, and then 4 vertical cuts were produced. The resulting vertical soil profiles were photographed with a digital camera (Nikon Coolpix 990) mounted on a tripod. The distance between camera and profile was equal for all cuts and the illumination from two headlamps was held constant; therefore, neither geometrical correction nor brightness adjustment was necessary. The pixel resolution was determined to be $0.4 \mathrm{~mm}$.

The profile sections were also photographed with a Cooled CCD Camera to produce concentration maps of the fluorescent tracer excitated by a xenon lamp and optically filtered according to its excitation spectrum (for details: see Aeby et al., 2001).

\section{IMAGE ANALYSIS}

The digital images from field and laboratory were processed with the method outlined in this section: First, the vertical profile section was cut out from the rest of the image using Adobe Photoshop (version 5.0.2) in order to isolate the relevant area. We also excluded large stones in the lower part of the profile from the analysis. Next, the mean level of the color channels was standardized to a reference common for all profiles to account for different illuminations depending on sun angle and weather conditions on the different excavation dates. A profile from 30 April 2001 was selected to be the reference for the Hannigalp field profiles, and a profile from 14 May 2001 for the Gd St Bernard profiles. We then applied an automated classification procedure to separate the pixels stained with Brilliant Blue tracer from the unstained profile pixels by identifying where the pixels of particular profile regions were located in the three-dimensional space of the red, green, and blue channels. In the lab profiles, the pixels representing the stained areas were clearly separated from the pixels representing nonstained soil (Fig. 4). In the field profiles from Hannigalp we noticed some overlapping of the stained pixels with the dark-brown pixels representing organic soil close to the surface. Since misinterpretation is possible in these situations, we assigned the pixels to the dark organic soil where overlapping occurred, thus minimizing the classification error.

The resulting maps of classified stained areas were processed further with the image analysis operations erosion and dilation that are usually applied (1) to eliminate erroneously classified single pixels, and (2) to fill in small gaps in a connected stained area. Finally, we calculated the number of stained pixels per row and divided them by the total number of pixels per row, resulting in an
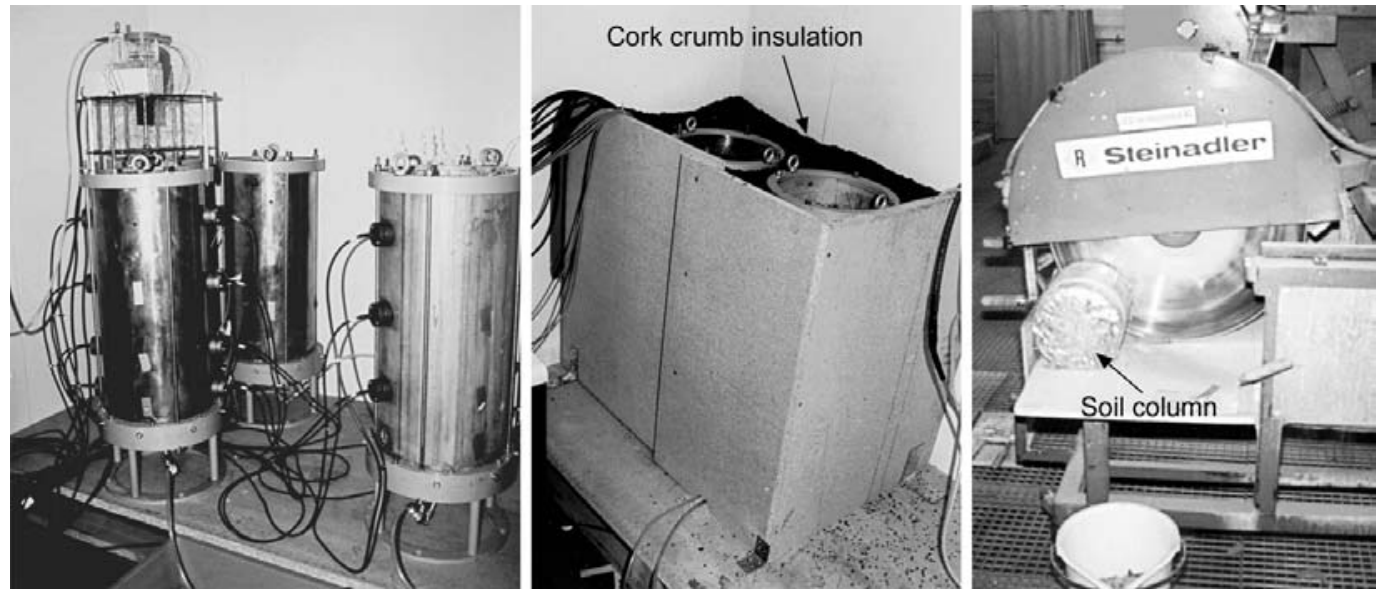

FIGURE 3. Image documentation of the laboratory irrigation experiment. Left: The columns in a steel cylinder with the measurement probes inserted from the side. The rotating sprinkler is placed on top of the left column. Center: During the freezing experiment the columns were insulated with cork crumbs. Right: The frozen columns were sawed using a circular saw. 

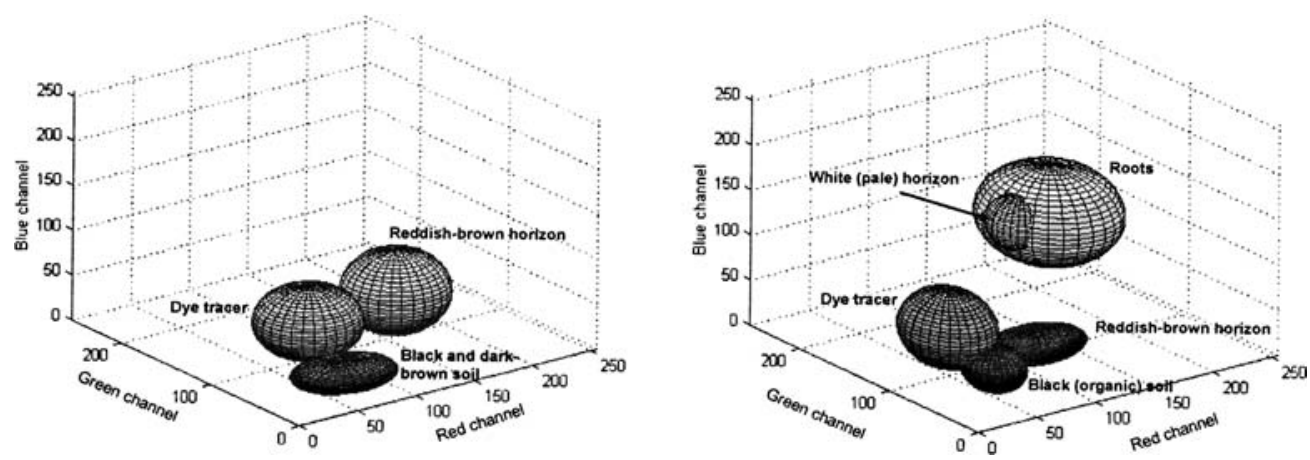

FIGURE 4. Ellipsoids enveloping different pixel groups in the three-dimensional RGB space. Each pixel group represents one specific soil layer or roots or the stained areas of the Hannigalp soil. Left: Soil column section. Right: Field profile.

areal fraction of stained area, for which the depth distribution was plotted.

\section{Results}

\section{FIELD EXPERIMENT}

\section{Weather Conditions and Snow Cover Development}

The meteorological conditions at the 2 sites varied during the 2 winters: During the first winter season (2000-2001) snowfall already formed a considerable snow cover by early November (Fig. 5), which prevented the soil from freezing at both sites. Throughout the entire season, the snowpack remained thick and steadily increased to a maximum of $103 \mathrm{~cm}$ at Hannigalp and $275 \mathrm{~cm}$ at Gd St Bernard. As a consequence, soil frost was not able to form at any time during the winter, except for a very superficial layer that was observed locally and
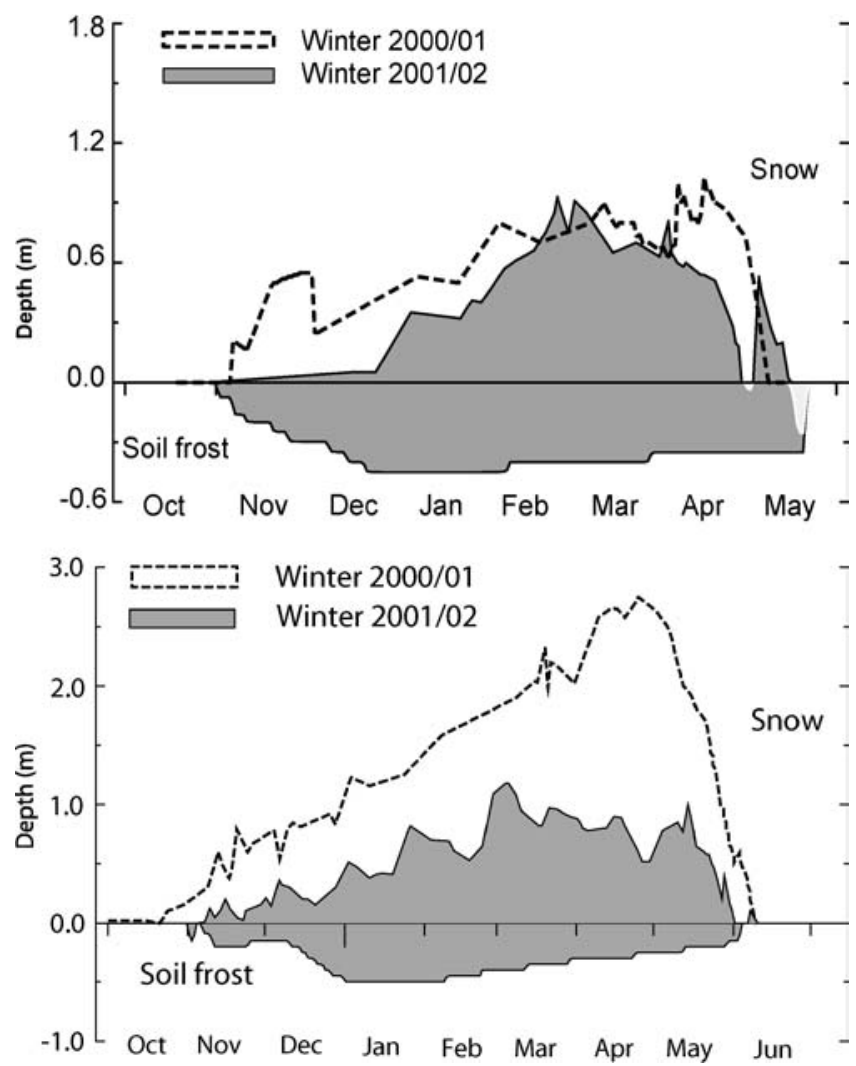

FIGURE 5. Measured snow depth and simulated frost boundary (Bayard, 2002) for the 2 experimental winter seasons at Hannigalp (top) and Gd St Bernard (bottom). for only a short time at Hannigalp. In contrast, November and December of the second winter were unusually dry with little snow precipitation in southern Switzerland. Thus, the cold air temperatures were not dampened by snow cover, and a deep, persistent soil frost formed. We observed maximum frost depths of $50 \mathrm{~cm}$ and $40 \mathrm{~cm}$ at Hannigalp and Gd St Bernard, respectively. After the beginning of January, snowfall set in and started to form a snowpack with a snow water equivalent comparable to normal winters. At Hannigalp, all the snow was melted by April, whereas at Gd St Bernard the snow was not completely melted before the beginning of June.

Depth profile measurements of soil water content (Bayard, 2002) indicated that the soil was relatively dry prior to both winters. At Hannigalp, we measured water contents of 0.17 to $0.25 \mathrm{~m}^{3} \mathrm{~m}^{-3}$ in the upper $60 \mathrm{~cm}$ of the soil, and at Gd St Bernard 0.22 to $0.45 \mathrm{~m}^{3} \mathrm{~m}^{-3}$ before both winters. Consequently, the soils had a high air-filled porosity at the onset of the snowmelt.

\section{Field Profiles Hannigalp}

In winter 2000-2001, when the soil remained unfrozen, the first profile excavation in mid-March confirmed that no liquid water had infiltrated to the snowpack bottom in the time since the tracer application. At the time of excavation the tracer was still concentrated in the few centimeters above the soil surface, and no tracer was observed in the soil. However, after the first major snowmelt event, which released approximately $50 \mathrm{~mm}$ of water from the snowpack, considerable areas of the reddish-brown B-horizon were stained with tracer between the depths of 30 and $50 \mathrm{~cm}$. Since minimal amounts of tracer were detected in the same excavation in the topsoil, we assumed a very local bypassing via roots or other preferential flow paths. Over the course of the snowmelt this observation was confirmed and reinforced. At the end of April and on 7 May, the excavated profiles contained large coherent zones with dye tracer in the lower part, near the bedrock. Dye was also recovered from the pale white layers and partly in the topsoil. We noted further evidence for preferential flow through the upper part of the soil and spreading farther down in the coarser soil material. As a concrete example of such rapid infiltration, Figure 6 shows an ant channel vertically penetrating the uppermost 10 $\mathrm{cm}$ of the soil, and colored roots of an Ericaceae shrub conducting the water preferentially to deeper depths. Preferential water infiltration may also be triggered by the highly water-repellent nature of the soil surface, which is a known source of unstable wetting fronts (Hendrickx et al., 1993).

The depth distribution of the stained area (Fig. 7) demonstrates that, with the exception of the organic-rich top 1-2 centimeters, no more than $50 \%$ of the cross-section was infiltrated by water down to the bedrock. The variability of dye tracer patterns between the profiles-even between profiles excavated on the same date-is 

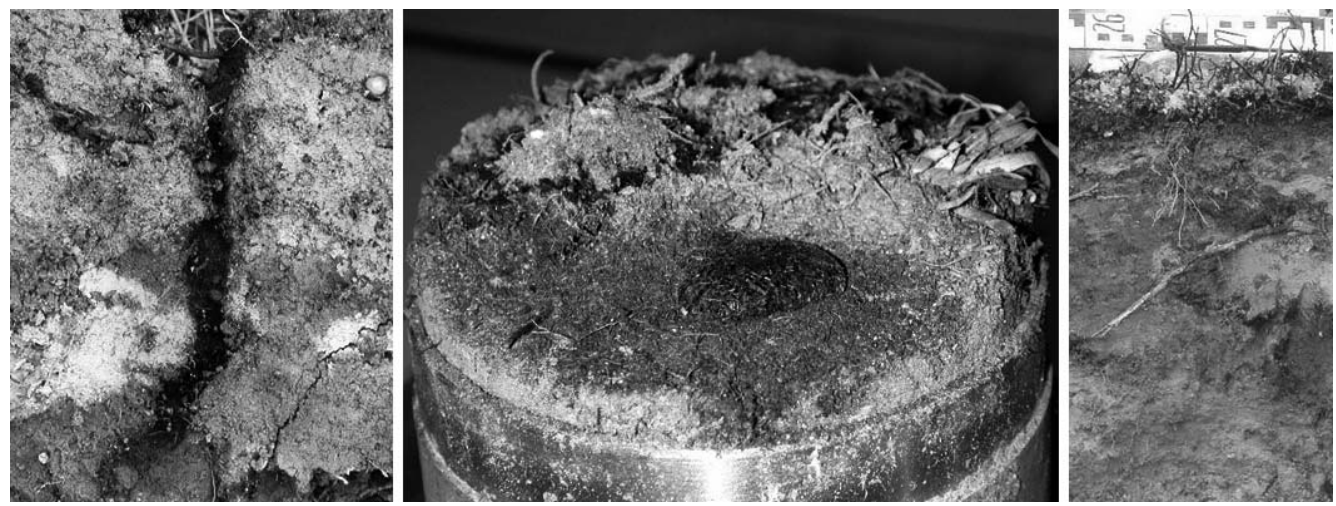

FIGURE 6. Triggers for preferential water infiltration observed at Hannigalp. Left: An ant channel with an extraordinary dye tracer concentration. Center: High water repellence of the soil surface, determined with the water-drop penetration method. Right: Roots of an Ericaceae shrub acting as a dominant water flow path from which the stained water spreads out to the adjacent pores.

distinct. Also, the depth distributions of the stained areas clearly show an increase in dye tracer penetration depth over the duration of the snowmelt.

In the second winter, the stained profiles showed influences of the soil frost. In the first stage of the snowmelt, the water infiltrated to a depth of $15-25 \mathrm{~cm}$, where it apparently met a discontinuous frozen layer (Fig. 8). It is, however, interesting that although the soil surface was initially frozen, the meltwater was able to enter the uppermost centimeters. At the start of the snowmelt, an ice layer of about $1-2 \mathrm{~cm}$ thickness formed at the base of the snowpack on the cold soil surface, which prohibited the water from infiltrating farther. Consequently, enhanced surface runoff was observed. These observations go hand in hand with surface runoff measurements on an adjacent plot using slope-parallel drain gutters (Bayard and Stähli, 2004): From these plots, approximately $20 \%$ of the total runoff occurred at the surface in this early stage of the snowmelt. Until 15 April, the zone of concentrated dye tracer moved somewhat downward (Fig. 7), which we interpret as a result of continuous thawing of the soil ice. Two weeks later, after all snow had melted (1 May), the depth distribution of stained areas looked very different. Although the soil was still partly frozen between 30 and $50 \mathrm{~cm}$ depth, the infiltrating water had carried most of the dye tracer to the lower half of the profile. In the coarse soil material the tracer spread over a large fraction of the profile. The distribution of dye tracer from the last excavation on 13 May, which took place after an intermediate snow accumulation and melting, corroborates this washing-out process, which was apparently not influenced by the soil frost.

\section{Field Profiles Gd St Bernard}

Excavating soil profiles at the $\mathrm{Gd} \mathrm{St}$ Bernard site was troublesome. First of all, the nearly 3-m-deep snowpack and the harsh winter climate provided unsuitable working conditions. A first attempt in early April fell victim to the prevailing weather. In addition, the Ranker soil with its large proportion of horizontally aligned slate stones made it difficult to create smooth vertical profiles. Nevertheless, we succeeded in photographing 4 profiles on 14 May and 4 profiles on 1 June, when almost the entire snow cover had melted. Upon excavation, we found the dye tracer to be much more diluted than planned due to the unexpected high quantities of meltwater. In addition, the natural grayish-brown color of the Ranker soil did not contrast with the blue tracer as nicely as the soil at Hannigalp. As a consequence, the visibility of the stained areas was moderate on 14 May and weak on 1 June. In spite of these difficulties, the basic nature of the water flow pattern was seen clearly. Infiltration through this soil occurred rather homogeneously. No evidence of preferential flow, as in the Hannigalp soil, was found. In the top $20-30 \mathrm{~cm}$ the soil was almost completely pervaded by the stained meltwater (Fig. 9). Toward the lower part of the profile, the fraction of stained area decreased. We believe, however, that this is not due to a channeling of the water to the lower part of the profile but rather is a consequence of strong dilution. The fact that the tracer was applied on a rather narrow band carries weight to the dilution, especially in the lower part of the profile (edge effect). Since the Gd St Bernard site was only studied in the first winter without soil frost, no conclusions regarding the effect of soil freezing could be made.

\section{COLD-CHAMBER EXPERIMENT}

The unfrozen soil column had a low water content $\left(\sim 0.08 \mathrm{~m}^{3}\right.$ $\mathrm{m}^{-3}$ ) prior to irrigtion. As in the in situ experiment at Hannigalp, the infiltration provided a very heterogeneous tracer pattern. In all of the 8 profile sections from the 2 unfrozen columns we observed patches of stained soil in the uppermost $20 \mathrm{~cm}$, indicating preferential flow. To illustrate the variation between the different cross-sections, Figure 10 shows the mean depth distribution and associated standard deviation (represented by horizontal bars) of the areal Brilliant Blue tracer coverage (above) and the fluorescent tracer concentration (below). For the most part, the standard deviation was larger than the mean value. Comparing the two different tracers, we found a fairly good correspondence between the depth distributions, even though the dye and the fluorescent tracer provide different information: areal coverage in the first case and absolute concentrations in the second. A linear regression analysis between the depth distributions of the two tracer properties (calculated for each profile section separately) yielded $\mathrm{R}^{2}$ values of up to 0.69 for the unfrozen soil and up to 0.91 for the frozen soil.

For the frozen soil columns, the infiltration pattern was quite uniform. All 10 cuts showed an accumulation of the stained water in the uppermost $5-10 \mathrm{~cm}$, distributed over less than half of the soil volume. The $10-15-\mathrm{cm}$-thick frozen zone was not bypassed by infiltrating water. Rather, the infiltration profile reflected that the top centimeters thawed up from the soil surface, allowing the water to enter. The soil material of these uppermost few centimeters was organic-rich and had a high porosity. Due to its dark color, the automatic detection of the dye tracer in this layer was more difficult than in the underlying reddish-brown or pale-white soil horizon; thus, some misinterpretation is possible.

\section{Discussion and Conclusions}

The tracer experiments in the laboratory and at the 2 field sites demonstrate which existing concepts of water infiltration into frozen or 
Winter 2000/01 (without soil frost)
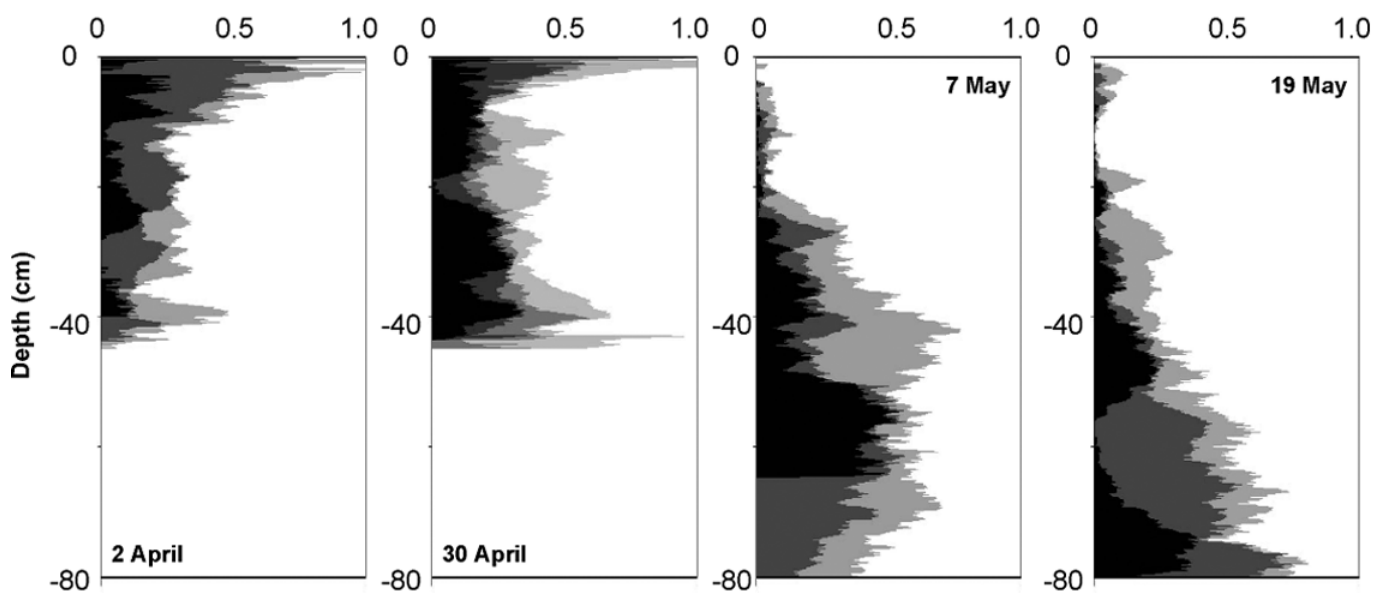

Areal coverage of dye tracer $(-)$

Winter 2001/02 (with soil frost)
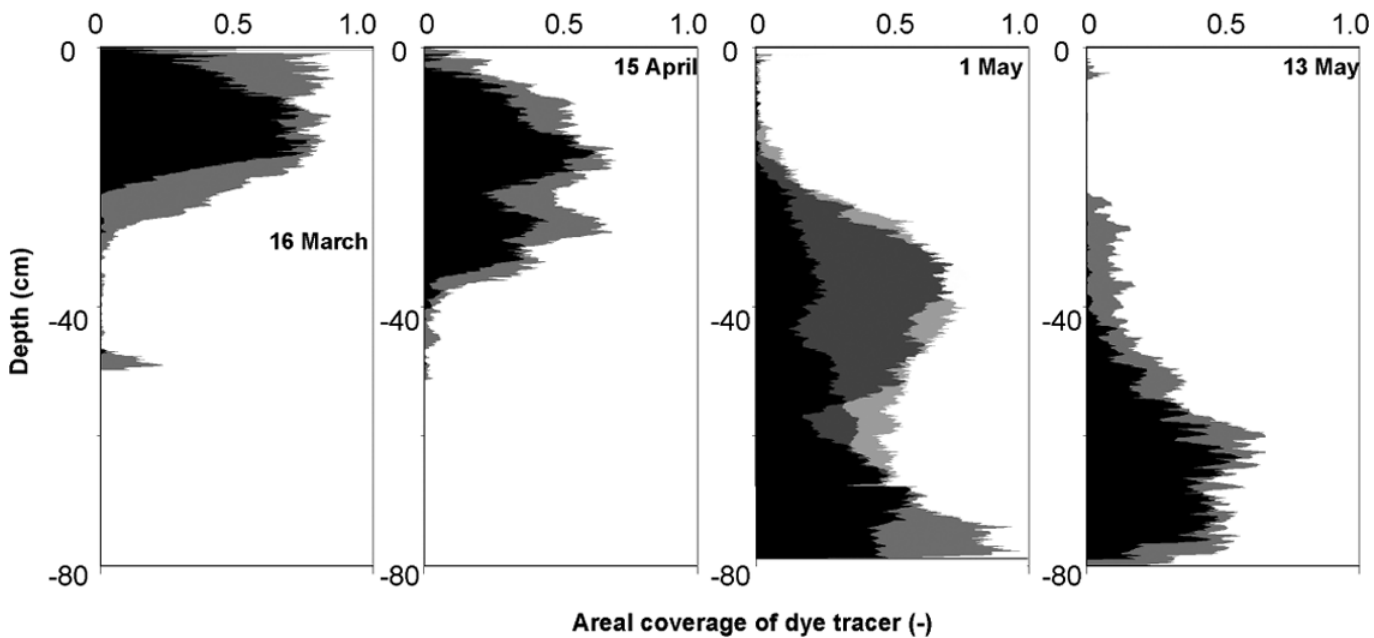

Hannigalp. Consecutive profiles from the same date superimposed on each other.

unfrozen soils are appropriate for such alpine environments by revealing the dominant water infiltration flow paths. Highly preferential water flow was observed in the soil from Hannigalp, in contrast to a very homogeneous pattern observed in the soil from Gd St Bernard. Consequently, two different model concepts are suitable for the simulation of the water transfer in these two soils: a multiflow domain approach in the first case and a simpler Richards-type approach in the latter case. Also, the tracer experiments identified the dominant triggers of the preferential water flow: the water repellence of the organic-rich surface and roots and ant channels, all of which rapidly direct the water to deeper depths.

Concerning the impact of frozen soil on the snowmelt infiltration, the study at Hannigalp showed that a frozen soil layer impedes rather than prevents water infiltration. Although the melted snow water transfers heat to the soil, the soil surface remains initially cold. This may create an ice layer at the base of the snowpack, which impedes water infiltration and increases surface runoff. According to our field observations, such an ice layer has a thickness of 1 to a few $\mathrm{cm}$. Its
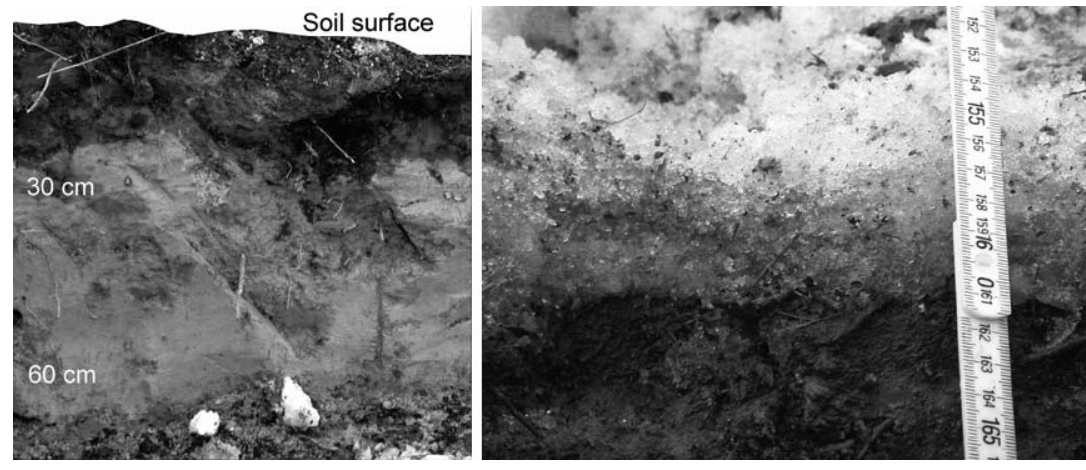

FIGURE 8. Left: Image of a soil profile excavated on 16 March 2002 showing the infiltrated meltwater concentrated in the uppermost $25 \mathrm{~cm}$ of the frozen soil. Right: During spring 2002 a thin ice layer formed on the soil surface due to melting and refreezing. 
influence on surface runoff was confirmed by water balance measurements on $6-\mathrm{m}^{2}$ plots, where surface runoff was collected with slopeparallel drain gutters (Bayard and Stähli, 2004). During the period with a basal ice layer, we measured 20 to $25 \%$ of the total runoff occurring at the surface, whereas in the previous year almost $100 \%$ of the snowpack outflow infiltrated the soil.

With regard to the applicability of the tracer method, we find that it is applicable at remote alpine locations. Provided that the soil contains a large portion of fine material, it is possible to excavate vertical profiles for visualization of the infiltration pathways down to the coarser soil or the bedrock, even when the soil is frozen. The image analysis procedures we used for filtering out the stained areas (supervised classification) is straightforward and can be automated for soil profiles with similar background color and illumination.

As a result of our study, we recommend taking into account the following points:

- The timing of the tracer application is crucial. It should take place late enough to avoid a prewinter rain or melt event, but not too late in order to minimize the disturbance of the snow cover. The tracer dose must be large enough in relation to the expected meltwater quantities to ensure visibility in the soil throughout the entire melt season. We recommend the tracer be applied as a powder (even though this might be problematic at windy locations) to minimize premelting dilution and avoid the buildup of a basal ice layer due to the irrigation.

- Harsh weather conditions and a thick snowpack hamper the excavation of the soil profiles and photo documentation. At Gd St Bernard we met our limits in the early stage of the snowmelt. Taking photographs of good enough quality to determine the stained areas of the profile was not always possible due to

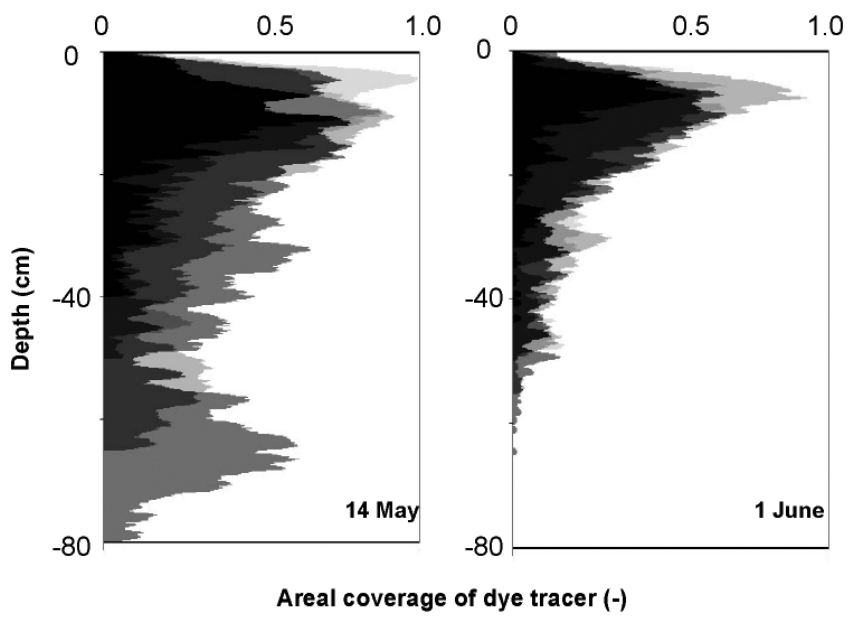

FIGURE 9. Depth profile of areal coverage of pixels stained with dye tracer for all profiles excavated on 2 dates of the 2001 snowmelt at $G d$ St Bernard (2450 $m$ a.s.l.). Consecutive profiles from the same date superimposed on each other.

heavy snowfall and high winds. Overall, we found that the sensitive equipment used to record the fluorescent tracer (multitracing detection device including a cooled CCD-camera and a setup of filters and mirrors) requires not only suitable weather but a steady power source and a means of transportation. Therefore, this equipment is more suited to laboratory studies than to field studies.

- The soil color should be taken into account when choosing a dye tracer. The Brilliant Blue FCF tracer used in this study
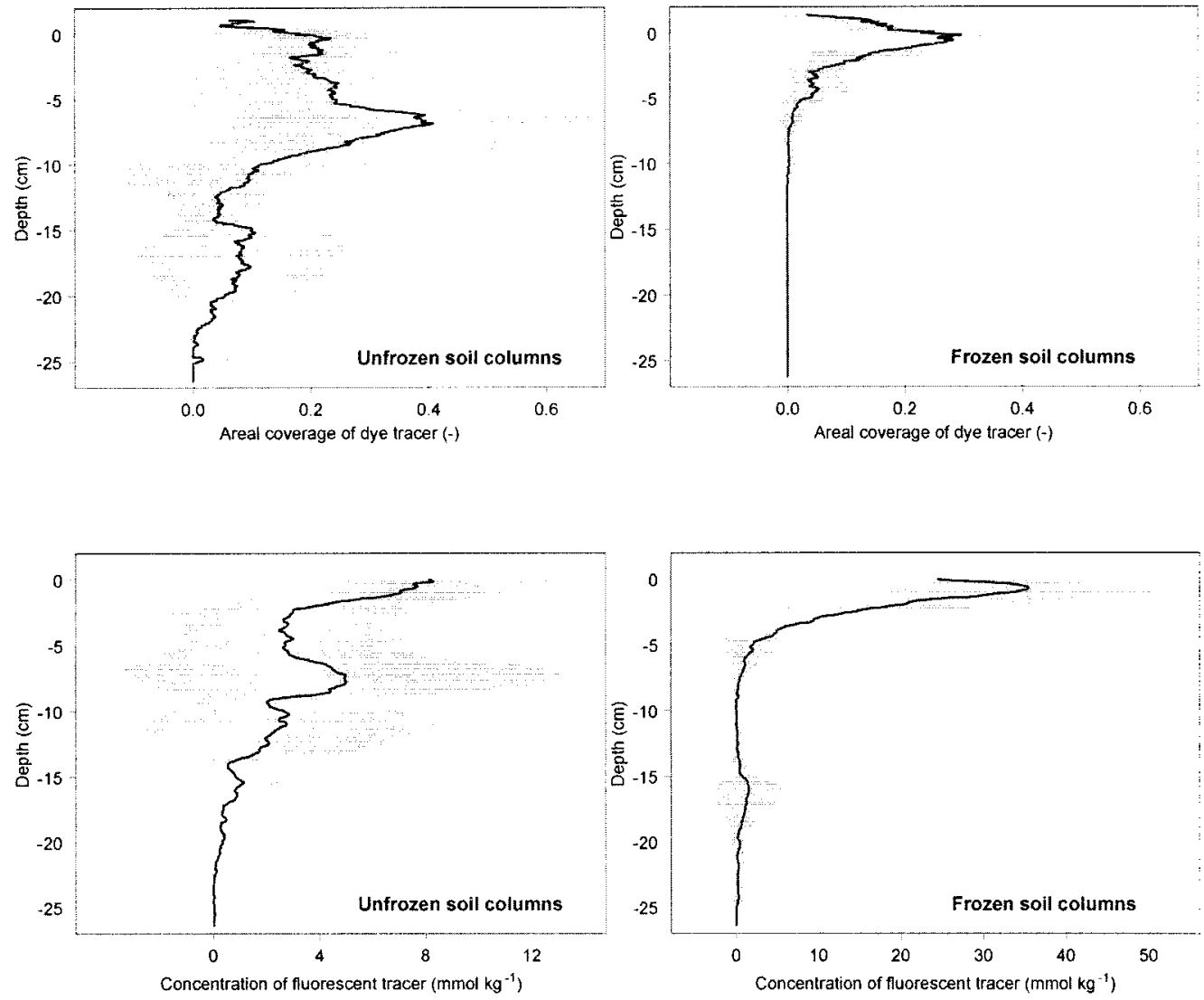

FIGURE 10. Depth distribution of areal coverage of pixels stained with the dye tracer (top) and fluorescent tracer concentration (bottom): mean \pm standard deviation for the 2 unfrozen soil columns (left) and the 2 frozen columns (right). 
contrasted very nicely the Hannigalp soil colors, except for the organic-rich thin top layer. On the other hand, in the dark brown-gray soil at Gd St Bernard, Brilliant Blue was more difficult to detect. To optimize the visibility of the tracer and also minimize the application dose, a tracer should be selected that provides the best contrast to the natural soil color.

The dye tracer experiments at Hannigalp and Gd St Bernard proved to be a valuable complement to standard soil water balance measurements, which in former studies had been used to make conclusions regarding the soil frost effect on the soil hydrology (e.g., Stadler et al., 1996; Stähli et al., 1999). The use of dye tracers facilitates the interpretation of very local soil water content measurements (with time domain reflectometry technique) in relation to slopeaveraging runoff measurements.

\section{Acknowledgments}

Carrying out dye tracer experiments during 2 winter seasons at such remote locations and under harsh conditions requires the assistance and support of several collaborators. We wish to express our gratitude to the following people who contributed in one way or another to the success of this study:

Jörg Leuenberger, Dominik Bänninger, Hans Wunderli, the staff at the Hannigalp ski resort, and the staff of the Gd St. Bernard monastery. Melissa Swartz corrected the language. Financial support was received from ETH Zürich and EPF Lausanne.

\section{References Cited}

Aeby, P., Schultze, U., Braichotte, D., Bundt, M., Moser-Boroumand, F., Wydler, H., and Flühler, H., 2001: Fluorescence imaging of tracer distributions in soil profiles. Environmental Science and Technology, 35(4): 753-760.

Bayard, D., 2002: The effect of seasonal soil frost on the alpine groundwater recharge and its sensitivity to a changing climate. Ph.D. dissertation, EPF Lausanne, Institute of Infrastructure, Resources, and Environment. 174 pp.
Bayard, D., and Stähli, M., 2004 (in press): Effects of frozen soil on the groundwater recharge in alpine areas. In Collins, D., de Jong, C., and Randzi, R. (eds.), Climate and Hydrology in Mountain Areas. London: John Wiley and Sons Ltd.

Bisdom, E. B. A., Dekker, L. W., and Schoute, J. F., 1993: Water repellency of sieve fractions from sandy soils and relationships with organic material and soil structure. Geoderma, 56: 105-118.

Flury, M., and Flühler, H, 1995: Tracer characteristics of Brilliant Blue FCF. Soil Science Society of America Journal, 59(1): 22-27.

Flury, M., Flühler, H., Jury, W. A., and Leuenberger, J., 1994: Susceptibility of soils to preferential flow of water: a field study. Water Resources Research, 30: 1945-1954.

Forrer I., Papritz, A., Kasteel, R., Flühler, H., and Luca, D., 2000: Quantifying dye tracers in soil profiles by image processing. European Journal of Soil Science, 51: 313-322.

Hendrickx, J. M., Dekker, L. W., and Boersma, O. H., 1993: Unstable wetting fronts in water repellent field soils. Journal of Environmental Quality, 22: 109-118.

Kulli, B., Stamm, C., Papritz, A., and Flühler, H., 2003: Discrimination of flow regions on the basis of stained infiltration patterns in soil profiles. Vadose Zone Journal, 2: 338-348.

Miller, R. D., 1980: Freezing phenomena in soils. In Hillel, D. (ed.), Applications of Soil Physics. New York: Academic Press, 254-299.

Singh, P., Spitzbart, G., Hubl, H., and Weinmeister, H. W., 1997: Hydrological response of snowpack under rain-on-snow events: a field study. Journal of Hydrology, 202(1-4): 1-20.

Stadler, D., Bründl, M., Wunderli, H., and Auckenthaler, A., 1996: Measurement of frost-induced snowmelt runoff in a forest soil. Hydrological Processes, 10: 1293-1304.

Stadler, D., Stähli, M., Aeby, P., and Flühler, H., 2000: Dye tracing and image analysis for quantifying water infiltration into frozen soils. Soil Science Society of America Journal, 64: 505516.

Stähli, M., Jansson, P.-E., and Lundin, L.-C., 1999: Soil moisture redistribution and infiltration in frozen sandy soils. Water Resources Research, 35(1): 95-103.

Ms submitted January 2003 